\title{
ACCOUNTING STUDENTS' PERFORMANCE IN DISTANCE EDUCATION: A STUDY FOCUSED ON SOCIODEMOGRAPHIC FACTORS
}

\author{
Vitor Hideo Nasu https://orcid.org/0000-0002-5176-6634 \\ Universidade de São Paulo, São Paulo, SP, Brazil
}

\begin{abstract}
This study aimed to investigate the relationship between accounting students' performance and sociodemographic variables (namely gender, employment, marital status, and ethnicity) in distance education. I collected data from the 2015 National Exam of Students' Performance, obtaining a final sample of 11,707 observations. Results indicated that male students outperformed female ones. Also, worker students have better performance than their colleagues. Married students obtained better performance than their single colleagues, but no relevant difference was found in comparison to other (divorced, widowed, etc.) students. Regarding ethnicity, white students outperformed other students (black, brown, and others).
\end{abstract}

Keywords: Distance education, Academic performance, Accounting education, Sociodemographic factors.

Manuscript first received: 2020-07-21. Manuscript accepted: 2020-08-03

Address for correspondence:

Vitor Hideo Nasu. Universidade de São Paulo, São Paulo, SP, Brazil. Email: vnasu@usp.br 


\section{INTRODUCTION}

Distance education (DE) is a representative phenomenon in the context of Brazil. Brazilian Association of Distance Education (ABED) shows significant advancements in its last annual report. From 2015 to 2016, the offer DE of primary level (middle school and high school) and graduate programs (master and doctorate) increased considerably (ABED, 2017). Similarly, the number of both informal and formal DE programs has been raised over the years. A noteworthy aspect in ABED's 2017 report is that the indicator of social networks' (e.g., Facebook) and digital applications' (e.g., Whatsapp ${ }^{\circledR}$ ) usage to deliver content in DE was demonstrated to be high in 2016 (ABED, 2017). It suggests that mobile technologies and informal means of communication are becoming more present and visible, even in formal education settings. Some challenges in DE should be emphasized though. Innovation in pedagogical methods is perceived as the most concerning of DE demands (ABED, 2017). Innovation technology and infrastructure are also among the most concerning characteristics education institutions should worry about to remain competitive. Finally, managers observe that administrative processes in DE require more efficiency (ABED, 2017).

Accounting is among the highest demanded undergraduate programs in Brazil, representing $7.2 \%$ of the total students enrolled in higher DE (ABED, 2017). Only Education (25.0\%), Management (13.7\%), and Social Service (7.4\%) programs have upper representativeness. This data denotes that Accounting is an essential field for the Brazilian job market and higher education. Likewise, it suggests that developing studies on the relationship between DE and accounting is opportune, particularly in the current context of Brazil and because DE and digital devices tend to be more explored in the future as technology advances. Moreover, recent influential literature reviews show a decrease of research on DE within the accounting domain (Apostolou, Dorminey, Hassell, and Rebele $\left.^{1}, 2015,2016,2017\right)$. I then take this opportunity to revisit the DE topic. More specifically, I examine the association between Brazilian accounting students' performance and sociodemographic variables in $D E$. Higher attention has been paid to the academic variables (e.g., GPA) when analyzing student performance. However, sociodemographic variables may also have an impact on academic achievement (Miranda, Lemos, Oliveira, and Ferreira, 2015) and a broader implication for students, faculty, and institutions. Here, I focus on four sociodemographic variables that have been found to be inconclusive or have been receiving less attention in accounting education: gender, employment, marital status, and ethnicity. Gender and employment present conflicting findings regarding their relationship with academic performance (Byrne and Flood, 2008; Gammie, Paver, Gammie, and Duncan, 2003; Koh and Koh, 1999; Miranda et al., 2015; Ravenscroft and Buckless, 1992). With respect to marital status and ethnicity, most accounting students' performance literature does not take these variables into account as predictors, despite their potential effects. Then, I try to shed more light on these four relationships.

This study seeks to contribute to the development of accounting students' academic performance literature in three main directions. First, the sociodemographic variables investigated in this study have inconclusive results concerning their relationship with academic performance. New empirical evidence is necessary to help building a more precise result and drawn implications from it. Second, albeit considerable body of research has been conducted in accounting face-to-face education settings (Byrne and Flood, 2008; Carpenter, Friar, and Lipe, 1993; Gammie et al., 2003; Koh and Koh, 1999; Nogueira, Costa, Takamatsu, and Reis, 2013; Seow, Pan, and Tay, 2014), less studies can be found in DE (e.g., Jagero and Masasi, 2011), which is becoming more important. Third, the unit of analysis of the most of the prior literature is the local undergraduate program (Byrne and Flood, 2008; Carpenter 
et al., 1993; Gammie et al., 2003; Jagero and Masasi, 2011; Koh and Koh, 1999; Nogueira et al., 2013; Seow et al., 2014). Instead, this study employs data from a national database and it matters for the development of a more general picture of accounting education and for external validity purposes.

The remainder of the paper is structured as follows. Next section discusses previous literature and develops the hypotheses. Method section describes the data, variables, and other methodological procedures. Results section brings the results and debates the findings. Conclusions section concludes and provides suggestions for future research.

\section{LITERATURE REVIEW AND HYPOTHESIS DEVELOPMENT}

Besides the most intuitive variables that can influence students' academic performance in DE (e.g. hours of study), I argue that sociodemographic factors also have potential to impact it and maybe are as important as academic variables to student's achievement. For this reason, in this study, I focus on four main aspects, which are: students' gender, marital status, ethnicity, and employment.

Most of the literature on the relationship between gender and academic performance in accounting education is out of the scope of DE. For example, Byrne and Flood's (2008), Nogueira et al. 's (2013), and Ravenscroft and Buckless's (1992) studies represent investigations about the impact of gender on students' performance in face-to-face education. Therefore, this study seeks to contribute by providing empirical evidence to help better understand this phenomenon in accounting $\mathrm{DE}$ as well.

Gender has been submitted to a conjunction of analyses by accounting researchers all over the world (Byrne and Flood, 2008; Gammie et al., 2003; Koh and Koh, 1999; Nogueira et al., 2013; Ravenscroft and Buckless, 1992; Seow et al., 2014). Gender analysis in educational settings is important to the extent to which it may produce findings that help instructors to design their courses accordingly to the students' needs (Taplin and Jegede, 2001). Also, distinct behaviors may come from students' gender (Ravenscroft and Buckless, 1992; Taplin and Jegede, 2001), such as different study habits or type of study (individual or group), which in turn may impact academic achievement.

Despite that, gender's influence on academic performance remains inconclusive (Byrne and Flood, 2008; Koh and Koh, 1999; Miranda et al., 2015; Ravenscroft and Buckless, 1992), once no systematic and consistent empirical evidence has been found. For example, Koh and Koh (1999) examined the performance of 526 students from a three-year accountancy undergraduate program, in Singapore. Regression analysis showed that male students outperformed female ones in the first and second year of the program $(\mathrm{p}<.05)$. But no statistically significant difference was found for the third-year students' performance. On the other hand, Gammie et al. (2003) investigated 132 students' performances from the accounting and finance program over the 1998-2000 period. Statistical tests revealed that female students obtained better performance than their male colleagues in the accounting course (a first-year course; $\mathrm{p}<.05$ ) and auditing module (a third-year course; $\mathrm{p}<.01$ ), though there were no significant differences between male and female students' performances for other four firstyear courses and three second-year courses of the program. Byrne and Flood (2008), Nogueira et al. (2013), Peiperl and Trevelyan (1997), in turn, found that gender is not a relevant determinant of academic performance $(\mathrm{p}>.10)$. Albeit these findings are related to face-to-face education, I do not present any relevant reason to expect different outcomes in DE context in terms of students' gender. Thus, based on prior literature and empirical findings, I formulate the first hypothesis: 


\section{H1 There is no relationship between academic performance and gender in accounting distance education.}

Association between placement in the job market and academic performance has several important implications for practice, particularly in accounting DE field. Students who often travel for work purposes are still able to participate in DE classes because of its flexibility. DE breaks the physical barriers found in face-to-face education and, similarly to married students, it allows worker students to reconcile their academic, personal, and professional lives. In contrast, excessive job appointments may produce lack of motivation to study. In Brazil, students know how difficult is to both work and study at the same time (Moura, Miranda, and Pereira, 2015). Working while studying is one of the main factors that students complain about that reduces their time to study (Moura et al., 2015). And it may get worse if the contents learned in classes are dissociated with work activities students develop. Additionally, students in DE must have responsibility and control about their academic behavior and assignments, otherwise, they might lose motivation to study and drop out. Also, students' anonymity in DE makes more comfortable for them to drop out as they feel less challenged by the instructor or social pressure to keep studying (Bryant, Schafer, and Kahle, 2005). Dropouts in DE are common and represent a challenge in contemporary education. A final critical point is that some students cannot stop working to exclusively dedicate to study because they need to help their family financially (Moura et al., 2015). This is the case of many students in Brazil. Thus, some students do not even work in the accounting area and it may impact their academic achievement considerably.

Empirical evidence on the relationship between employment and academic performance is inconclusive (Miranda et al., 2015). Miranda et al.'s (2015) literature review shows three studies in the business education field that found a positive association, three more that indicated a negative association, and one study that found no association between work hours and student performance. Krieg and Uyar (2001), for instance, found that work hours have a negative impact on performance of students from the Business and Economics Statistics discipline. Oppositely, Jagero and Masasi (2011) detected a positive correlation between work experience and academic performance of accounting students of an Open Distance Learning University. However, in the case of Jagero and Masasi's (2011) study, students' work experience was obtained before entering the accounting undergraduate program. Still, Peiperl and Trevelyan (1997) identified that work experience does not predict academic performance. Putting empirical findings and prior literature into perspective, the second hypothesis establishes that:

H2 There is no relationship between academic performance and employment in accounting distance education.

Marital status is an important sociodemographic variable that has not been received too much attention by accounting education researchers. Students' marital status can influence multiple behaviors. Al-Kandari and Vidal (2007), for example, found that marital status is significant correlated with health responsibility $(\mathrm{F}=3.3 ; \mathrm{p}<.05)$, physical activity $(\mathrm{F}=3.1 ; \mathrm{p}<.05)$, nutrition $(\mathrm{F}=$ $3.4 ; \mathrm{p}<.05)$, and stress management $(\mathrm{F}=5.3 ; \mathrm{p}<.01)$. At first, it seems to be disconnected from academic performance, but health care may have indirect effects on it. Another interesting aspect comes from Poyrazli and Kavanaugh's (2006) study. They found that married students have lower levels of adjustment strain than single students when going abroad to study. A potential explanation is that social needs of married students are fulfilled at home by their spouses or families, reducing their level of strains (Poyrazli and Kavanaugh, 2006). Despite that, marital status was not found 
to be a relevant predictor of students' achievement ( $p>.05)$. Cheung and Kan (2002) also found no significant association between academic performance and marital status in a distance-learning business communication course from Open University of Hong Kong.

One may conjecture that married students have lower performances than single ones since they probably have to spend more time caring about their children or attend other appointments that single people do not. Thus, married students have less time to dedicate to study. Single students, in turn, may have more free time and they could use it to improve their academic performance by participating in complementary education projects to assist their learning, such as undergraduate research. ABED (2017) and Radford (2011) indicate that students who have dependent (e.g., children) or were married are more likely to participate in DE classes or to take DE programs. This is probably because DE helps married students to conciliate their time between job/social appointments and education. For example, DE does not demand from students to go to college building, saving time for other activities. In this sense, in web-based education, Erdogan, Bayram, and Deniz (2008) found a statistically significant difference between married and single students' performances $(\mathrm{t}=2.87 ; \mathrm{p}<.01)$. Married students outperformed their single counterparts. Likewise, Peiperl and Trevelyan (1997) found that unmarried students scored less than married ones ( $\mathrm{t}$ Final $=3.479 ; \mathrm{p}<.001 ; \mathrm{t}$ Individual $=3.051 ; \mathrm{p}<.01$ ). Peiperl and Trevelyan (1997) think that it may be due to students' spouses financial, household, and emotional support in reducing stress originated by the MBA program. Despite the results of Cheung and Kan's (2002) and Poyrazli and Kavanaugh's (2006) studies, which found no association between academic performance and civil status, Erdogan et al.'s (2008) and Peiperl and Trevelyan's (1997) empirical findings indicate a small advantage in favor of married students. Then, the third hypothesis is as follows:

\section{H3 There is a positive relationship between academic performance and married students in} accounting distance education.

Ethnicity is another important topic with little attention in contemporary accounting students' academic performance literature. The study of ethnicity, with a focus on minority students, could be valuable for those responsible for admitting and conceiving scholarships (Gist, Goedde, and Ward, 1996), as well as to structure other education politics. Most studies dedicated to examining the determinants of accounting students' performance do not take ethnicity into consideration despite its potential effects. Gender variable, on the other hand, is as easy as ethnicity one to collect (e.g., through survey) but appears more frequently in the literature (Byrne and Flood, 2008; Gammie et al., 2003; Gist et al., 1996; Koh and Koh, 1999; Nogueira et al., 2013; Ravenscroft and Buckless, 1992). However, especially over the last decade, the accounting field has been recognizing the value of diversifying the profession. For example, Pathways Commission (2012) and U. S. Department of the Treasury (2008) report that diversifying the entrants into the accounting profession would be fundamental for a number of reasons: (i) organizations are becoming more diverse in terms of culture and ethnicity; (ii) long-term success of the accounting profession; (iii) promoting different perspectives within accounting workplace; (iv) underrepresentation and homogeneity are not acceptable from a societal and business point of view; and (v) accounting profession should reflect the demographic changes of the global economy. However, Brazilian accounting education has to dedicate more efforts on this topic, since just a few projects seem to be concerned about plural ethnicities in the accounting profession.

Critical aspects still regarding the ethnicity and education contexts are racism, discrimination, and bullying. According to Dotterer and Lowe (2015), discrimination is a relevant factor for the 
development of minorities. Performance gaps between minority and non-minority youth reveal that minority group lag behind the non-minority one in high school, college and, more broadly, in academic achievement (Dotterer and Lowe, 2015). It supports that negative prior life and academic experiences of students may influence their academic performance years later. Unfortunately, discrimination in the Brazilian society remains evident and found many times institutionalized in organizations. Other societies may have the same problem. Therefore, with a particular look at Brazil, Gomes (2003) states that pedagogical practices should be elaborated and employed in order to combat racial discrimination. Some empirical evidence supports no significant correlation between ethnicity and students' performance though (Cerezo and Chang, 2013; Hackett, Hackett, Betz, Casas, and RochaSingh, 1992). However, within accounting education, Carpenter, Friar, and Lipe (1993) found that minorities have worse academic achievement than non-minorities. Thus, given the Brazilian reality and the empirical finding for accounting education, the fourth hypothesis predicts that:

H4 There is a significant difference in performance of accounting students from distinct ethnicities in distance education.

\section{METHOD}

\section{Data}

This study utilized the microdata from the 2015 National Exam of Students' Performance (ENADE), which are publicly available. ENADE is a high-scale national exam that aims to evaluate the quality of higher education in Brazil through undergraduate students' performances. It is periodically conducted by National Institute for Educational Studies and Research Anísio Teixeira (INEP), a nationally well-known and reliable institution. The last ENADE edition that Brazilian accounting students took was in 2015 by the time I collected the data. 2015 ENADE was mandatory only for undergraduate students who were almost graduated (last year of the accounting programs) and they were selected according to the INEP's sampling procedures.

2015 ENADE comprehended both objective and subjective questions about General Formation (GF) and Specific Component (SC) contents (more details about GF and SC questions are provided in the "Performance Variables" subsection.). GF questions seek to assess basic concepts and competencies of students. On the other hand, SC questions are related to specific programmatic contents of undergraduate programs. In the case of this study, the accounting undergraduate programs. Final performance (FP) of students is then measured by the weighted average of correct answers for GF (25\%) and SC (75\%) questions. Additionally, students answer an electronic survey, including 68 socioeconomic, cultural, and academic questions (e.g., gender, age, family income, etc). Because this study has a specific objective, only relevant variables remained in the dataset (student performance and variables reported in Table 2).

A total of 65,483 accounting students who were about to graduate took the 2015 ENADE. However, 14,535 students were from DE, representing the population of this study. From the population, I chose to eliminate those students who had missing values in GF and SC performances and, consequently, in FP, even though missing values in other variables were kept. After this procedure, an intermediate sample of 12,018 observations was obtained. INEP also provided data about reasons that invalidate students' performance on the 2015 ENADE, such as administrative problems. Then, students with invalid performances originated from any motivation were excluded. I 
also find a student with error measurement in the gender variable, which was dropped. Thus, 11,707 observations constituted the final sample. It represents $80.5 \%$ of the population of this study and $17.9 \%$ of total accounting students that did the 2015 ENADE. These sample procedures were employed to avoid problems with interpretation of the results. Table 1 details the procedures and the number of observations, as well as its representativeness.

Table 1. Sample procedures, observations, and representativeness

\begin{tabular}{lccc}
\hline Procedures & \# of obs & $\mathbf{\% ~ ( 1 ) ~}$ & \% (2) \\
\hline $\begin{array}{l}\text { Total number of students } \\
\text { (face-to-face education and distance education) }\end{array}$ & 65,483 & & $100.0 \%$ \\
(-) Face-to-face education students & $(50,948)$ & & $77.8 \%$ \\
$=$ Population of the study & 14,535 & $100.0 \%$ & $22.2 \%$ \\
$\begin{array}{l}\text { (-) Missing values in performance variables } \\
\text { (GF, SC, FP) }\end{array}$ & $(2,517)$ & $(17.3 \%)$ & $3.8 \%$ \\
$=$ Subtotal & 12,018 & $82.7 \%$ & $18.4 \%$ \\
$\begin{array}{l}\text { (-) Invalid performances and measurement error in } \\
\text { the ENADE's database }\end{array}$ & $(311)$ & $(2.1 \%)$ & $0.5 \%$ \\
\hline = Final sample & $\mathbf{1 1 , 7 0 7}$ & $\mathbf{8 0 . 5 \%}$ & $\mathbf{1 7 . 9 \%}$ \\
\hline
\end{tabular}

I used blocked adaptive computationally efficient outlier nominators (BACON) command on the final sample to detect potential outliers, considering $p=.15$ (Weber, 2010). Because no multivariate outlier was identified, all observations of the final sample were used in the analysis.

\section{Performance Variables}

As previously described, students' final performance on the 2015 ENADE is measured by objective and subjective questions. They are also categorized into GF and SC questions. GF questions demand general knowledge from students to be answered. This type of question aims to capture students' vision and competencies to react and to argue critically about contemporary issues of national and international contexts. Technology advancement, globalization, social responsibility, biodiversity, arts, and culture are some of the subjects of GF questions (INEP, 2015). SC questions, on the other side, are related to specific contents of the undergraduate programs' curriculum. Regarding the accounting program, SC questions comprised the following subjects: accounting theory, financial accounting, managerial and cost accounting, auditing, governmental accounting, analysis of financial statements, regulation, quantitative methods, and professional ethics (INEP, 2015).

Students' final performances are represented by the weighted average of correct answers for GF $(25 \%)$ and SC (75\%) questions. GF performance, SC performance (GFP and SCP, respectively and henceforth) and FP assume a value on a quantitative scale that can range from 0 to 100 points. I explore all these three types of performances (GFP, SCP, and FP) to test the hypotheses of the study, although a major focus is on FP. 


\section{Sociodemographic Variab les}

Students' sociodemographic information was gathered through the INEP's online survey, which was mandatory for students who took 2015 ENADE, even though missing values can be found in some sociodemographic variables. Students reported their age, gender, marital status, and other variables. For purposes of this study, I specifically analyze four sociodemographic factors: (i) gender (GEN); (ii) placement in the job market (JOB); (iii) marital status (MST); (iv) ethnicity (ETN); Gender is a binary variable, 1 for male students and 0 for female. Placement in the job market (JOB) is a binary variable, 1 for employed and 0 otherwise. Marital status is a categorical variable (Single, Married, and Other). Finally, Ethnicity is a qualitative variable with four categories: White; Black; Brown; and Other (indigenous and descendant of oriental people). I must emphasize that all sociodemographic information was reported by the students.

\section{FINDINGS}

Table 2 describes students' characteristics in terms of sociodemographic variables. The majority of students are female (61.6\%), married (49.2\%), white (53.4\%), with a monthly family income between three and six Brazilian minimum wages (36.6\%), and have a job $(89.7 \%)$. The average age of participants is 32.93 years old $(\mathrm{SD}=8.35$ years old). It is important to highlight that all sociodemographic information was self-reported by the students.

Subsequently, Table 3 shows descriptive statistics of students' performances (GFP, SCP, and FP). Accounting students' GFP is the highest among all three types of performances with a mean equal to 49.8 points, following by FP (36.5 points) and SCP (32.0 points). Minimum values indicate that at least one of the students scored zero points on GF and SC questions. It may suggest relevant presence of deficiencies in the educational process and/or students' lack of motivation to study for ENADE. Medians can be considered low since the range scale starts at 0.0 and ends at 100.0 points. Then, taking in consideration students' FP, I observe that most of the students could not even reach the midterm of the scale (median $=35.3$ points $<$ scale midterm $=50.0$ points). It may also suggest problems in the accounting learning process in Brazil.

To test hypothesis H1, I conducted tests for mean differences with all three performance measures (GFP, SCP, and FP). As Shapiro-Wilk's and Levene's tests, respectively, indicated that data do not follow a normal distribution and do not have homogeneity of variances, I employed Welch's t-test. Table 4 shows the results. According to the statistical tests, male outperformed female students in all three performance measures $(\mathrm{p}<.01)$. Research shows inconclusive results about gender differences in terms of academic achievement (Byrne and Flood, 2008; Koh and Koh, 1999; Ravenscroft and Buckless, 1992). Here, I obtained new evidence in DE, supporting the conjecture that male students have better performance than female ones. This result is inconsistent with Gammie et al.'s (2003), distinct from Byrne and Flood's (2008) and Nogueira et al.'s (2013), and congruent with Koh and Koh's (1999) and Seow et al.'s (2014). Then, evidence rejects hypothesis H1, which predicted that there is no significant association between gender and accounting students' performances. Some implications can be emphasized. If empirical evidence shows significant differences between male and female students' performances, one may think that accounting educational processes are not fair, and it could influence job market entrance because students with higher performances usually obtain better work positions. 
Table 2. Students' sociodemographic information

\begin{tabular}{|c|c|c|}
\hline Students' information & Frequency & $\%$ \\
\hline Age (AGE) - mean and standard deviation & 32.93 & 8.35 \\
\hline Gender (GEN) & 11,707 & $100.0 \%$ \\
\hline Male & 4,490 & $38.4 \%$ \\
\hline Female & 7,217 & $61.6 \%$ \\
\hline Marital Status $(M S T)^{\mathrm{b}}$ & 11,611 & $100.0 \%$ \\
\hline Single & 4,466 & $38.5 \%$ \\
\hline Married & 5,714 & $49.2 \%$ \\
\hline Other & 1,431 & $12.3 \%$ \\
\hline Ethnicity $(E T N)^{\mathrm{b}}$ & 11,611 & $100.0 \%$ \\
\hline White & 6,197 & $53.4 \%$ \\
\hline Black & 773 & $6.7 \%$ \\
\hline Brown & 4,357 & $37.5 \%$ \\
\hline Other (indigenous and oriental descendants) & 284 & $2.4 \%$ \\
\hline Family income, per month $(I N C)^{\mathrm{b}}$ & 11,611 & $100.0 \%$ \\
\hline 0-3 minimum wages ${ }^{\mathrm{a}}$ & 5,172 & $44.5 \%$ \\
\hline 3-6 minimum wages ${ }^{\mathrm{a}}$ & 4,244 & $36.6 \%$ \\
\hline $6+$ minimum wages $^{\mathrm{a}}$ & 2,195 & $18.9 \%$ \\
\hline$J o b(J O B)^{2}$ & 11,611 & $100.0 \%$ \\
\hline Job & 10,418 & $89.7 \%$ \\
\hline No Job & 1,193 & $10.3 \%$ \\
\hline
\end{tabular}

aBrazilian minimum wage at the time of 2015 ENADE data collection was 724 BRL (187.42 USD).

${ }^{\mathrm{b}} \mathrm{A}$ total of 11,611 students were analyzed as MST, ETN, INC, JOB, and HST variables presented 96 missing values each.

'I utilized the ethnicity classification of 2015 ENADE, regardless how Brazilians are seen/categorized by other countries. Thus, "white", "black", "brown", and "other" categories should be understood and relativize in the context of Brazil.

Table 3. Accounting students' academic performance: GFP, SCP, and FP

\begin{tabular}{lcccccc}
\hline Performance & $\mathbf{N}$ & Mean & SD & Median & Min & Max \\
\hline GFP & 11,707 & 49.8 & 15.56 & 50.1 & 0.0 & 96.8 \\
SCP & 11,707 & 32.0 & 13.56 & 30.5 & 0.0 & 96.5 \\
FP & 11,707 & 36.5 & 12.22 & 35.3 & 0.0 & 86.4 \\
\hline
\end{tabular}

Table 4. Accounting students' performance by gender: GFP, SCP, and FP

\begin{tabular}{lcccccc}
\hline \multirow{2}{*}{ Performance } & \multicolumn{2}{c}{ Male $(\mathbf{N}=\mathbf{4 , 4 9 0})$} & \multicolumn{2}{c}{ Female $(\mathbf{N}=\mathbf{7 , 2 1 7})$} & \multirow{2}{*}{ t } & p (two-tailed) \\
\cline { 2 - 5 } & Mean & SD & Mean & SD & & -5.6 \\
GFP & 50.8 & 16.3 & 49.1 & 15.1 & & 0.00 \\
SCP & 34.6 & 14.9 & 30.4 & 12.4 & -15.9 & 0.00 \\
FP & 38.7 & 13.4 & 35.1 & 11.2 & -15.0 & 0.00 \\
\hline
\end{tabular}


Hypothesis $\mathrm{H} 2$ predicts that there is no relationship between employment and accounting students' academic performance. I carried out Welch's t-tests once data violated the homogeneity of variance assumption. Table 5 demonstrates the results. All three performance measures are statistically significant $(\mathrm{p}<.01)$. Worker students outperformed their colleagues who do not have a job. This evidence does not support hypothesis H2. Other variables are possibly influencing the relationship between students' performance and placement in the job market. Another explanation for this result is that job helps the students to learn accounting. For example, internships or trainees may learn from their work experience, which in turn could impact their academic performance positively. In Brazil, it is very common for accounting students to work and study at the same time. Thus, this evidence supports that students should work in order to improve their achievement. This finding is aligned with Jagero and Masasi's (2011), contrary to the Krieg and Uyar's (2001), and different from Peiperl and Trevelyan's (1997).

Table 5. Accounting students' performance by employment: GFP, SCP, and FP

\begin{tabular}{lcccccc}
\hline \multirow{2}{*}{ Performance } & \multicolumn{2}{c}{ Job $(\mathbf{N}=\mathbf{1 0 , 4 1 8})$} & \multicolumn{2}{c}{ No Job $(\mathbf{N}=\mathbf{1 , 1 9 3})$} & \multirow{2}{*}{ t } & p (one-tailed) \\
\cline { 2 - 4 } & Mean & SD & Mean & SD & & \\
\hline GFP & 49.9 & 15.6 & 48.8 & 14.8 & -2.5 & 0.01 \\
SCP & 32.3 & 13.7 & 30.3 & 12.5 & -5.1 & 0.00 \\
FP & 36.7 & 12.3 & 34.9 & 11.1 & -5.1 & 0.00 \\
\hline
\end{tabular}

Hypothesis $\mathrm{H} 3$ establishes that there is a positive relationship between married students and academic performance. Results of statistical tests are shown in Table 6. Levene's tests indicated that only GFP and SCP have homogeneous variance $(\mathrm{p}>.05)$. Therefore, ANOVA was utilized. For FP, Welch's ANOVA was used instead because it lacked homogeneity of variance. Both ANOVA and Welch's ANOVA tests were relevant $(\mathrm{p}<.01)$, suggesting the existence of a significant difference among performances of students from, at least, two distinct categories of marital status. To identify these categories, I carried out Bonferroni's post-hoc test for GFP and SCP and Games-Howell's posthoc test for FP.

Regarding students' GFP, I observe that single students have lower performance than their colleagues in the "Other" (mean difference $=1.63 ; \mathrm{p}<.01)$ and "Married" (mean difference $=1.39$; $\mathrm{p}<.01)$ categories of marital status. Similar results were found for SCP and FP. These findings are expected according to the literature utilized to formulate hypothesis H3. Thus, based on this empirical evidence, I support the idea that there is a positive relationship between married students and academic performance in accounting distance education.

One explanation would be that students' spouse or family support is important for academic motivation (Peiperl and Trevelyan, 1997). Another alternative explanation is that other relevant variables may also be influencing the relationship between academic achievement and marital status. Cheung and Kan's (2002) and Poyrazli and Kavanaugh's (2006) findings differ from those obtained by this study. However, Erdogan et al.'s (2008) and Peiperl and Trevelyan's (1997) results are congruent. The results obtained by this study can be useful particularly for married students to decide whether to take a face-to-face or a DE accounting program. 
Finally, no significant difference was found between performances of students from "Married" and "Other" categories $(\mathrm{p}>.10)$. Complementary studies are necessary to address this issue about the lack of difference between performances of married and "other" students (divorced, widower, etc.).

Table 6. ANOVA, Welch's ANOVA, and post-hoc tests for marital status

\begin{tabular}{lccccc}
\hline Performance & $\begin{array}{c}\text { Homogeneity of } \\
\text { variance }\end{array}$ & Which test & F & prob F & Post-hoc test \\
\hline GFP & Yes & ANOVA & 11.94 & 0.00 & Bonferroni \\
SCP & Yes & ANOVA & 45.23 & 0.00 & Bonferroni \\
FP & No & Welch's ANOVA & 45.19 & 0.00 & Games-Howell \\
\hline GFP & $\mathbf{N}$ & Mean & SD & Single & Married \\
\hline Other & 1,431 & 50.55 & 15.47 & $1.63^{* * *}$ & 0.24 \\
Single & 4,466 & 48.92 & 15.44 & & $1.39^{* * *}$ \\
Married & 5,714 & 50.31 & 15.59 & & Married \\
\hline SCP & $\mathbf{N}$ & Mean & SD & Single & 0.35 \\
Other & 1,431 & 32.71 & 13.54 & $2.16^{* * *}$ & $2.51^{* * *}$ \\
Single & 4,466 & 30.55 & 13.27 & & Married \\
Married & 5,714 & 33.06 & 13.56 & & 0.20 \\
\hline FP & $\mathbf{N}$ & Mean & SD & Single & $2.23^{* * *}$ \\
\hline Other & 1,431 & 37.18 & 12.27 & $2.03^{* * *}$ & \\
Single & 4,466 & 35.16 & 11.97 & & \\
Married & 5,714 & 37.39 & 12.31 & & \\
\hline Ne. & & & & & \\
\hline
\end{tabular}

Note. ${ }^{* * *} \mathrm{p}<.01 ;{ }^{* *} \mathrm{p}<.05 ;{ }^{*} \mathrm{p}<.10$. I also conducted Tukey's, Scheffe's, and Sidak's post-hoc tests for GFP and SCP, obtaining very similar results. For FP, I carried out Tamhane's and Dunnet T3's post-hoc tests as well, which indicated consistent results with Games-Howell's test.

Hypothesis H4 predicts that accounting students from different ethnicities have distinct performances for reasons explained in the literature review section. Table 7 exhibits the results. Levene's test pointed out that GFP has homogeneity of variance $(\mathrm{p}>.05)$, while SCP and FP do not $(\mathrm{p}<.05)$. GFP was then submitted to ANOVA and SCP and FP to Welch's ANOVA. Low F probabilities $(\mathrm{p}<.01)$ denote that there is a relevant difference among performances of students from at least two distinguished categories of ethnicity. Bonferroni's and Games-Howell's post-hoc tests were conducted to find which categories differ.

Results of students' GFP indicate a significant distinction between white and brown students (mean difference $=1.64 ; \mathrm{p}<.01$ ). White students outperformed brown students. For SCP, I observe that white students scored significantly higher than all their colleagues from other categories of ethnicity $(\mathrm{p}<.01)$. Performance mean differences are significant for white and black students, white and brown students, and white and other students (indigenous and oriental descendant). Same results were found for FP. In Brazil, white people had a better job and education opportunities in the past, particularly because slavery issues. I think these scenarios can be extended to some other countries, where the social and work relation between black and white people was similar to Brazil. Findings are consistent with the conjecture that there is a significant difference in performance of students from distinct ethnicities and can support political decisions within accounting education. Therefore, 
this study obtained empirical evidence that offers full support for hypothesis H4. For this reason, education policies and pedagogical practices that aim to reduce inequality of opportunity deserve constant research.

Table 7. ANOVA, Welch's ANOVA, and post-hoc tests for ethnicity

\begin{tabular}{|c|c|c|c|c|c|c|}
\hline Performance & \multicolumn{2}{|c|}{ Homogeneity of variance } & Which test & $\mathbf{F}$ & prob $F$ & Post-hoc test \\
\hline GFP & \multicolumn{2}{|c|}{ Yes } & ANOVA & 9.51 & 0,00 & Bonferroni \\
\hline $\mathrm{SCP}$ & \multicolumn{2}{|c|}{ No } & $\begin{array}{l}\text { Welch's } \\
\text { ANOVA }\end{array}$ & 38.70 & 0,00 & Games-Howell \\
\hline FP & \multicolumn{2}{|c|}{ No } & $\begin{array}{l}\text { Welch's } \\
\text { ANOVA }\end{array}$ & 37.32 & 0,00 & Games-Howell \\
\hline GFP & $\mathbf{N}$ & Mean & SD & White & Black & Brown \\
\hline Other & 284 & 49.54 & 15.97 & 0.95 & 0.29 & 0.69 \\
\hline White & 6,197 & 50.49 & 15.58 & & 0.66 & $1.64 * * *$ \\
\hline Black & 773 & 49.83 & 15.75 & & & 0.98 \\
\hline Brown & 4,357 & 48.85 & 15.35 & & & \\
\hline SCP & $\mathbf{N}$ & Mean & SD & White & Black & Brown \\
\hline Other & 284 & 31.01 & 13.74 & $2.29 * * *$ & 0.65 & 0.38 \\
\hline White & 6,197 & 33.30 & 13.92 & & $2.94 * * *$ & $2.67 * * *$ \\
\hline Black & 773 & 30.36 & 12.73 & & & 0.28 \\
\hline Brown & 4,357 & 30.64 & 13.00 & & & \\
\hline FP & $\mathbf{N}$ & Mean & SD & White & Black & Brown \\
\hline Other & 284 & 35.66 & 12.33 & $1.96 * * *$ & 0.42 & 0.45 \\
\hline White & 6,197 & 37.61 & 12.53 & & $2.37 * * *$ & $2.41 * * *$ \\
\hline Black & 773 & 35.24 & 11.56 & & & 0,04 \\
\hline Brown & 4,357 & 35.20 & 11.72 & & & \\
\hline
\end{tabular}

Note. ${ }^{* *} \mathrm{p}<.01 ; * * \mathrm{p}<.05 ; * \mathrm{p}<.10$. In addition, I performed Tukey's, Scheffe's, and Sidak's post-hoc tests for GFP, which produced very similar results. For SCP and FP, I ran Tamhane's and Dunnet T3' post-hoc tests as alternatives for Games-Howell's. Results are consistent among the three tests.

I must emphasize that I tried to analyze data through regression models. However, linear regression via Ordinary Least Square was not employed as normal residuals and heteroskedasticity assumptions were not satisfied, according to the Shapiro-Wilk's and Breusch-Pagan/Cook-Weisberg's tests. I then chose to use multinomial logistic regression through the transformation of GFP, SCP, and FP into categorical variables, but once more assumption was violated. Hausman-McFadden's test suggested that independence of irrelevant alternative assumption was not met $(\mathrm{p}<.05)$. Because data did not obey regressions assumptions, I decided to not analyze them through these statistical techniques. Despite that, previous statistical procedures are still valid in testing the hypotheses.

A final effort was done toward the use of multiple correspondence analysis (MCA). I transformed GFP, SCP, and FP into categorical variables which I called "GFP2", "SCP2" and "FP2", respectively. GFP2, SCP2, and FP2 are qualitative variables with three categories each (High, Medium and Low performance). I used $33^{\text {rd }}$ and $67^{\text {th }}$ percentiles to form the three categories (High: 100-67 percentile; Medium: 66-34 percentile; Low: 33-0 percentile). Then, I ran chi-squared tests to verify associations between academic performance and sociodemographic variables (gender, marital status, ethnicity, 
and employment). Since results were similar to all three performances (GFP2, SCP2, and FP2), I reported only those regarding FP2. Table 8 shows chi-squared statistics and significance. I observe that most of the associations are relevant $(\mathrm{p}<.10)$, suggesting that MCA is appropriate to visualize data.

Table 8 - Chi-squared statistics and significance for FP2 and sociodemographic variables

\begin{tabular}{lcccc}
\hline Chi-squared & GEN & MST & ETN & JOB \\
\hline FP2 & $176.19^{* * *}$ & $73.40^{* * *}$ & $96.93^{* * *}$ & $14.67^{* * *}$ \\
GEN & & $50.33^{* * *}$ & $36.32^{* * *}$ & $153.39^{* * *}$ \\
MST & & $16.00^{* *}$ & 3.09 \\
ETN & & & $22.75^{* * *}$ \\
\hline
\end{tabular}

$* * * \mathrm{p}<.01 ; * * \mathrm{p}<.05 ; * \mathrm{p}<.10$.

Figure 1 represents the associations between students' performance and sociodemographic factors. It can be noted that high performances are more related to male, married, white, and worker students, as previous results of this study supported. In contrast, single and brown students are more associated with low performance. Although black and unemployed students are isolated, they are closer to low performance as well. Students with other marital statuses (divorced, widower etc.), other ethnicities (indigenous and oriental descendant), and female ones are more associated with medium performance. MCA reinforces prior findings of this study.

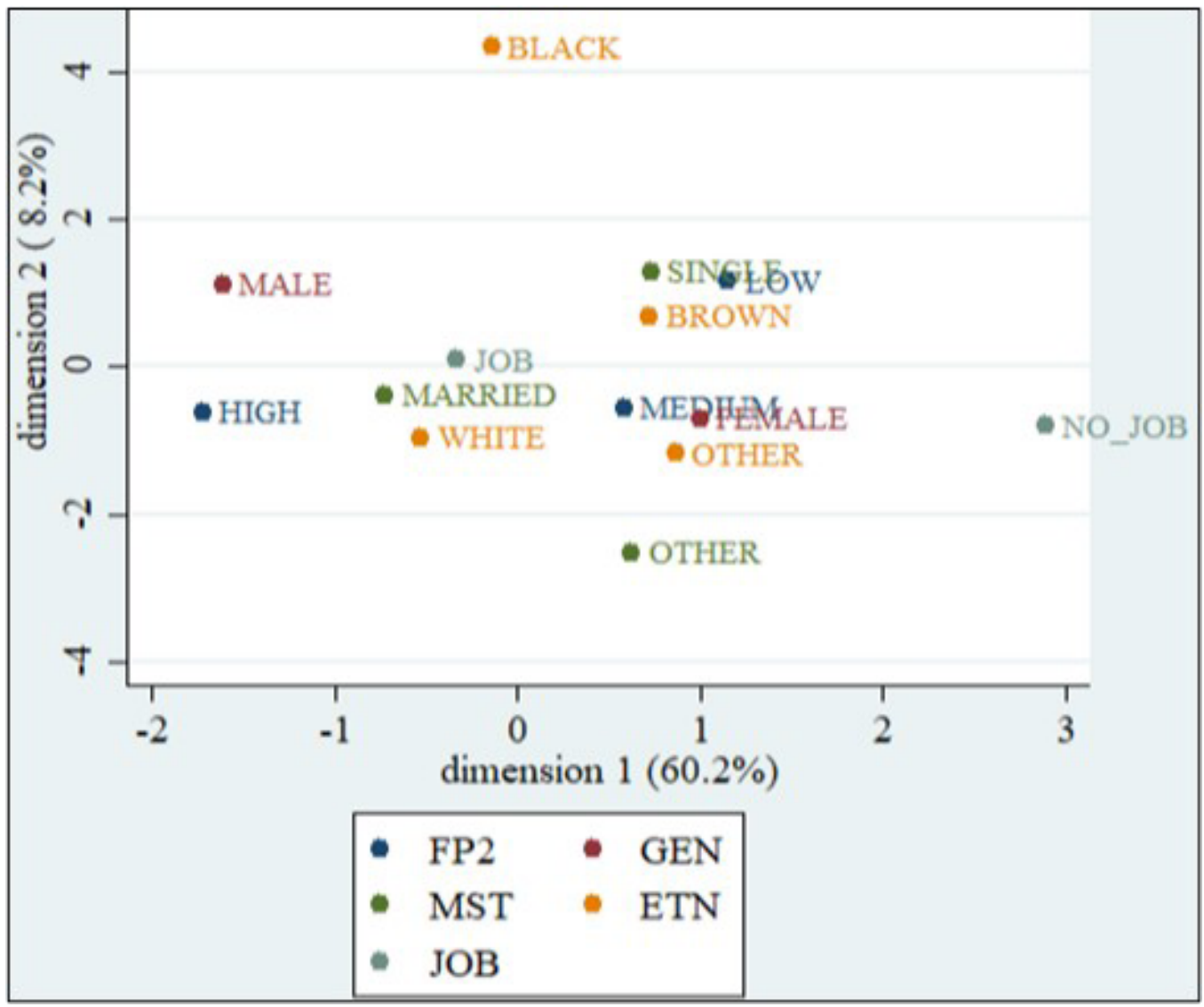

Figure 1. MCA Plot 


\section{CONCLUDING REMARKS}

This study sought to examine the accounting students' performance with a focus on sociodemographic variables. Specifically, I investigated the relationship between academic performance and four variables: (i) gender; (ii) marital status; (iii) ethnicity; and (iv) employment. For this end, I collected data from the 2015 ENADE, obtaining a final sample of 11,707 observations. Four hypotheses were established, which results are discussed below.

Hypothesis $\mathrm{H} 1$ defined that there is no association between students' gender and academic performance. Welch's t-tests pointed out that male outperformed female students. It suggests a positive relationship between male students and academic performance. Thus, $\mathrm{H} 1$ is rejected. Hypothesis $\mathrm{H} 2$ established that there is no relationship between student performance and employment, but Welch's $\mathrm{t}$-tests indicated that worker students outperformed students without jobs. Therefore, hypothesis $\mathrm{H} 2$ is not supported. Hypothesis $\mathrm{H} 3$ stated that there is a positive association between married students and academic performance. According to the Bonferroni's and Games-Howell's post-hoc tests, results showed that single students scored less than married and other students. I then was able to find evidence to support hypothesis H3. Finally, hypothesis H4 predicted that there would be significant differences among performances of students from distinct ethnicity categories. This hypothesis found full support since evidence indicated that, in general, white students outperformed their colleagues.

This study offers some important implications for accounting education and possibly other fields. First, descriptive statistics of students' performances (Table 3) indicated that the Brazilian accounting educational processes in DE may have some problems, once most of the students' FP could not reach the scale midterm. Rethinking how to provide and increase a quality accounting learning process in a national-scale should be in the agenda of accounting educators and researchers in Brazil. Pathways Commission's (2012) actions have been important efforts to improve accounting education in the U.S. and Brazilian accounting educators and politicians could use it as an example. Second, significant differences between male and female students' performances were found. Researchers should find ways to reduce them to provide more equal education process. Favoring male over female students - or vice versa - has several implications, including the opportunity to get good positions in the job market. However, I must recognize that differences in performance in terms of students' gender may be caused by mediator factors that I did not consider in the analysis. Third, married students outperformed single students. This result supports that DE is a modality of education that can benefit married students by providing conciliation of education and professional appointments and promoting closer contact with children and spouses. In addition, financial and emotional support that comes from spouses and family may configure as one of the explanations for this result as well. Although non-married students may have more time, it does not necessarily mean that the students spend time studying. Fourth, differences among performances of students with distinguished ethnicities suggest that previous experiences or opportunities were not equivalent among the accounting students with distinct ethnicities. It may be the case of students in some other countries where a certain ethnicity is more associated with lower family income, for example. For this reason, affirmative policy plays an essential role in social and educational contexts and these findings also have implications for economic, cultural, and political spheres, especially when seen from the perspective of admitting students in higher education. Ultimately, based on empirical evidence obtained for hypothesis H4, I would encourage students to get a job during the undergraduate course. Professional experience seems to assist students' performance. 
Main limitations of this study can be summarized in three points: (i) I was not able to perform complementary quantitative tests that could have contributed to a deeper understanding on the relationship between academic performance and sociodemographic factors. For example, regression models could not be analyzed as their assumptions were not satisfied. Additional data are needed to better explore the association between sociodemographic variables and students' performance in DE; (ii) sociodemographic information was provided by students. Thus, results should be observed with cautious, given that restriction on self-reported data is applied to this study; and (iii) some essential variables (e.g. grade point average, attendance etc.) were not available and it also constrained the analysis to the extent to which I was not able to run complementary or more specific tests.

Finally, I provide some insights for future research. Longitudinal studies that examine the relationship between sociodemographic factors and academic performance are essential as they allow to capture the effect of a variable of interest on a response variable over time. For instance, what happens to accounting students' performance if their family income increases or decreases over time? Or what is the immediate effect after the students start/stop working in the accounting/non-accounting area? Another important aspect to investigate is how sociodemographic factors are potential moderators or mediators of the impact of academic variables (e.g., attendance, hours of study, reading, etc.) on students' performances in DE. Ultimately, as technology gains more attention and mobility, especially in DE (ABED, 2017), research on what students' sociodemographic characteristics predict the higher propensity of using and accepting mobile technologies in DE (e.g., chat groups through Whatsapp ${ }^{\circledR}$ ) is equally encouraged.

\section{REFERENCES}

Al-Kandari, F., \& Vidal, V. L. (2007). Correlation of the health-promoting lifestyle, enrollment level, and academic performance of College of Nursing students in Kuwait. Nursing and Health Sciences, 9(2), 112-119. https://doi.org/10.1111/j.1442-2018.2007.00311.x

Apostolou, B., Dorminey, J. W., Hassell, J. M., \& Rebele, J. E. (2015). Accounting education literature review (2013-2014). Journal of Accounting Education, 33(2), 69-127. https://doi.org/10.1016/j. jaccedu.2015.04.001

Apostolou, B., Dorminey, J. W., Hassell, J. M., \& Rebele, J. E. (2016). Accounting education literature review (2015). Journal of Accounting Education, 35, 20-55. https://doi.org/10.1016/j. jaccedu.2016.03.002

Apostolou, B., Dorminey, J. W., Hassell, J. M., \& Rebele, J. E. (2017). Accounting education literature review (2016). Journal of Accounting Education, 39(1), 1-31. https://doi.org/10.1016/j. jaccedu.2017.03.001

Brazilian Association of Distance Education. (2017). 2016 Brazilian Census for Distance Learning. Retrieved from http://abed.org.br/censoead2016/Censo_EAD_2016_ingles.pdf

Bryant, S. M., Schafer, B. A., \& Kahle, J. B. (2005). Distance Education: A Review of the Contemporary Literature. Issues in Accounting Education, 20(3), 255-272. https://doi.org/10.2308/iace.2005.20.3.255

Byrne, M., \& Flood, B. (2008). Examining the relationships among background variables and academic performance of first year accounting students at an Irish University. Journal of Accounting Education, 26(4), 202-212. https://doi.org/10.1016/j.jaccedu.2009.02.001

Carpenter, V. L., Friar, S., \& Lipe, M. G. (1993). Evidence on the performance of accounting students: race, gender, and expectations. Issues in Accounting Education, 8(1), 1-17. 
Cerezo, A., \& Chang, T. (2013). Latina/o Achievement at Predominantly White Universities. Journal of Hispanic Higher Education, 12(1), 72-85. https://doi.org/10.1177/1538192712465626

Cheung, L. L. W., \& Kan, A. C. N. (2002). Evaluation of Factors Related to Student Performance in a Distance-Learning Business Communication Course. Journal of Education for Business, 77(5), 257-263. https://doi.org/10.1080/08832320209599674

Dotterer, A. M., \& Lowe, K. (2015). Perceived discrimination, parenting, and academic adjustment among racial/ethnic minority adolescents. Journal of Applied Developmental Psychology, 41, 71-77. https://doi. org/10.1016/j.appdev.2015.08.003

Erdogan, Y., Bayram, S., \& Deniz, L. (2008). Factors that influence academic achievement and attitudes in web based education. International Journal of Instruction, 1(1), 31-47. Retrieved from http://www.e-iji. net/dosyalar/iji_2008_1_3.pdf

Gammie, E., Paver, B., Gammie, B., \& Duncan, F. (2003). Gender differences in accounting education: an undergraduate exploration. Accounting Education, 12(2), 177-196. https://doi. org/10.1080/0963928032000091765

Gist, W. E., Goedde, H., \& Ward, B. H. (1996). The Influence of Mathematical Skills and Other Factors on Minority Student Performance in Principles of Accounting. Issues in Accounting Education, 11(1), 49-60. Retrieved from http://search.proquest.com/docview/210932176?accountid=14717

Gomes, N. L. (2003). Cultura negra e educação. Revista Brasileira de Educação, (23), 75-85. https://doi. org/10.1590/S1413-24782003000200006

Hackett, G., Hackett, G., Betz, N. E., Casas, J. M., \& Rocha-Singh, I. A. (1992). Gender, ethnicity, and social cognitive factors predicting the academic achievement of students in engineering. Journal of Counseling Psychology, 39(4), 527-538. https://doi.org/10.1037/0022-0167.39.4.527

Instituto Nacional de Estudos e Pesquisas Anísio Teixeira. (2015). Portaria INEP $n^{\circ}$ 220, de 10 de junho de 2015. Retrieved from http://download.inep.gov.br/educacao_superior/enade/legislacao/2015/ciencias contabeis_portaria_inep_n220_10062015.pdf

Jagero, N., \& Masasi, N. J. (2011). How prior academic exposure affect students performance in undergraduate accounting course in Tanzania. International Journal of Business \& Management Tomorrow, 1(1), 1-19. Retrieved from https://s3.amazonaws.com/academia.edu.documents/32848533/ IJBMT_Oct-2011.pdf?AWSAccessKeyId=AKIAIWOWYYGZ2Y53UL3A\&Expires=1515781909\&S ignature $=\mathrm{aJ} 6 \mathrm{DaerbvzXq} \% 2 \mathrm{BUe} 5 \mathrm{dbs} \% 2 \mathrm{~B} 8 \mathrm{eo} \% 2 \mathrm{FtcQ} \% 3 \mathrm{D} \&$ response-content-disposition=inline $\% 3 \mathrm{~B}$ filename\%3DIJBMT_Oct-2011.pdf\#page=149

Koh, M. Y., \& Koh, H. C. (1999). The determinants of performance in an accountancy degree programme. Accounting Education, 8(1), 13-29. https://doi.org/10.1080/096392899331017

Krieg, R. G., \& Uyar, B. (2001). Student performance in business and economics statistics: Does exam structure matter? Journal of Economics and Finance, 25(2), 229-241. https://doi.org/10.1007/ BF02744525

Miranda, G. J., Lemos, K. C. da S., Oliveira, A. S. de, \& Ferreira, M. A. (2015). Determinantes do Desempenho Acadêmico na Área de Negócios. Revista Meta: Avaliação, 7(20), 175-209. https://doi. org/10.22347/2175-2753v7i20.264

Moura, A. C. da R., Miranda, G. J., \& Pereira, J. M. (2015). Desempenho acadêmico em ciências contábeis: turno noturno versus diurno. Enfoque: Reflexão Contábil, 34(1), 57-70. https://doi.org/10.4025/enfoque. v34i1.23020 
Nogueira, D. R., Costa, J. M. da, Takamatsu, R. T., \& Reis, L. G. dos. (2013). Fatores que impactam o desempenho acadêmico: uma análise com discentes do curso de ciências contábeis no ensino presencial. Revista de Informação Contábil, 7(3), 51-62. Retrieved from https://periodicos.ufpe.br/revistas/ ricontabeis/article/viewFile/7991/8063

Pathways Commission. (2012). The Pathways Commission: Charting a national strategy for the next generation of accountants. Retrieved from http://commons.aaahq.org/posts/a3470e7ffa

Peiperl, M. A., \& Trevelyan, R. (1997). Predictors of performance at business school and beyond. Journal of Management Development, 16(5), 354-367. https://doi.org/10.1108/02621719710174534

Poyrazli, S., \& Kavanaugh, P. R. (2006). Marital status, ethnicity, academic achievement, and adjustment strains: The case of graduate international students. College Student Journal, 40(4), 767-780. Retrieved from https://s3.amazonaws.com/academia.edu.documents/37635758/2006_College_Student_J_Article.pd f?AWSAccessKeyId=AKIAIWOWYYGZ2Y53UL3A\&Expires $=1515781712 \&$ Signature $=3$ LGKIDxfNu 75bEftPr87pL5YLu8\%3D\&response-content-disposition=inline\%3B filename\%3DMarital_Status_Et

Radford, A. W. (2011). Learning at a distance: Undergraduate enrollment in distance education courses and degree programs. Retrieved from https://nces.ed.gov/pubs2012/2012154.pdf

Ravenscroft, S. P., \& Buckless, F. A. (1992). The effect of grading policies and student gender on academic performance. Journal of Accounting Education, 10(1), 163-179. https://doi.org/10.1016/07485751(92)90023-X

Seow, P.-S., Pan, G., \& Tay, J. (2014). Revisiting the determinants of students' performance in an undergraduate accountancy degree programme in Singapore. Global Perspectives on Accounting Education, 11, 1-23. Retrieved from http://ink.library.smu.edu.sg/soa_research\%5Cnhttp://ink.library. smu.edu.sg/soa_research/1247

Taplin, M., \& Jegede, O. (2001). Gender Differences in Factors Influencing Achievement of Distance Education Students. Open Learning: The Journal of Open, Distance and e-Learning, 16(2), 133-154. https://doi.org/10.1080/02680510120050307

U. S. Department of the Treasury. (2008). Final Report of the Advisory Committee on the Auditing Profession to the U.S. Department of the Treasury. In Advisory Committe on the Audit Profession. Retrieved from https://www.treasury.gov/about/organizational-structure/offices/Documents/final-report. pdf

Weber, S. (2010). Bacon: An Effective way to Detect Outliers in Multivariate Data Using Stata (and Mata). The Stata Journal: Promoting Communications on Statistics and Stata, 10(3), 331-338. https://doi. org/10.1177/1536867X1001000302

\section{NOTES}

This series of literature review on accounting education considers six journals (Advances in Accounting Education, Accounting Education, Global Perspectives in Accounting Education, Issues in Accounting Education, Journal of Accounting Education, and The Accounting Educators' Journal), which can be considered the most relevant in the accounting education field internationally. Apostolou et al.'s $(2015,2016,2017)$ literature reviews comprise the 2013-2016 period. 